\title{
It's More than Just Interpreting: Educational Interpreting Interns' Experiences in Rural Settings
}

\author{
Amber E. Marchut ${ }^{\circledR}$, Millicent M. Musyoka, M. Diane Clark \\ Department of Deaf Studies and Deaf Education, Lamar University, Beaumont, TX, USA \\ Email: mclark22@lamar.edu
}

How to cite this paper: Marchut, A. E., Musyoka, M. M., \& Clark, M. D. (2019). It's More than Just Interpreting: Educational Interpreting Interns' Experiences in Rural Settings. Psychology, 10, 1003-1024. https://doi.org/10.4236/psych.2019.107066

Received: May 8, 2019

Accepted: June 21, 2019

Published: June 24, 2019

Copyright $\odot 2019$ by author(s) and Scientific Research Publishing Inc. This work is licensed under the Creative Commons Attribution International License (CC BY 4.0).

http://creativecommons.org/licenses/by/4.0/

\section{(c) (i) Open Access}

\begin{abstract}
Transitioning from classroom learning and content to internship is not always streamlined and in the field of educational interpreting for deaf and hard of hearing students, this is especially challenging. Literature demonstrates limited understanding, knowledge, and studies regarding this transition along with limited provisions for support and guidance. A specific interpreter undergraduate preparatory program addressed this challenge through following four student interns in various rural educational settings to learn from their experiences using qualitative content analysis. Three themes were identified: violation of interns experiences, learning on the job, and coming to love the job. Recommendations from interns and data were made in how to better prepare future cohorts as well as providing findings that similar programs could use. They include course improvements, more specialized practicum experiences, and placement of two interns at the same educational placement. Findings can be used to improve the field of educational interpreting and interpreter preparation programs.
\end{abstract}

\section{Keywords}

Educational Interpreting, Interpreter Preparation Program, Deaf Students, American Sign Language

\section{Introduction}

Experiential learning is an approach frequently used to provide real-life experiences for students, and an internship is an instance of this approach. Internships provide students with real-life experiences that are often not provided in a classroom. Numerous postsecondary programs require students to complete at least one internship for graduation, and internships provide students with an 
opportunity to network and find a possible job after graduation. A challenge with an internship is the alignment of classroom content and internship preparation. As faculty members within the Department of Deaf Studies and Deaf Education (DSDE) at Lamar University, we aimed to address this challenge in our program regarding our interpreting students to help them prepare to become K-12 interpreters. Here the purpose of an internship is first discussed and then more information about educational interpreters is presented.

\subsection{Internship as Experiential Learning Opportunities}

Internships are supervised work experiences that provide students with an opportunity to transfer the experiential learning of their college work to the professional world, with the support and guidance of their faculty (Aldas, Crispo, Johnson, \& Price, 2010; Chinomona \& Surujlal, 2012; Coco, 2000; Gavigan, 2010; O'Neil, 2010). Practicum and internship are the two most common forms of experiential learning in higher education where students engage in constructive learning, critical reflection, and professional development (Janet, 2009; Gavigan, 2010). Constructive learning during internship allows students to apply "real-world" experiences to academic content and to use this knowledge to make informed decisions about their career paths (Simons et al., 2012). Also, internships support students' professional development by providing them opportunities for networking (Janet, 2009). Additionally, internships help to transition from the classroom to the job (Chinomona \& Surujlal, 2012; Coco, 2000).

Gavigan (2010) reported that the most significant benefit from an internship was the transformation of students' knowledge. As in Simons et al. (2012), students reported that their internship experiences enhanced their understanding of content knowledge, their ability to contribute to the welfare of the community, and their capacity to achieve their career goals. Based on students' responses, internship transformed their interpersonal communication skills, cultural competence, social responsibility, and helped them to mature (Cook, Parker, \& Pettijohn, 2004; Stichman \& Farkas, 2005).

Additionally, students' internships benefit both the university and the individual program (Kramer-Simpson, 2018; Simons et al., 2012). Simons et al. (2012) found that field supervisors and faculty indicated that practicum/internships can be used to strengthen university-community partnerships. Kramer-Simpson (2018) documented and characterized interactions between student interns and their mentors in the workplace as offering perspectives on student learning and enculturation that can help implement program improvements which will equip students with relevant knowledge and skills currently needed in the field. Based on this research, we now turn to the field of interpreters in general and then to the more specific field of educational interpreting.

\subsection{Interpreters}

Interpreting is a highly specialized skill that requires the ability to translate one 
language into another by decoding, deconstructing and reconstructing the meaning of what is being said, and considering specific word choices that best fit the speaker and the context. This skill includes providing the equivalent message from the original language in the translated language, including implicit messages and prosody. Interpreters not only focus on translating one language into another, but they also have a responsibility for cultural facilitation by observing body language, noting social cues, and responding in a way that is unobtrusive and respectful to all involved parties. American Sign Language (ASL) requires yet an additional skill, that of converting languages across modalities, a visual to an auditory modality or an auditory to a visual one.

Just like any other interpreter, an ASL interpreters' role varies depending on the purpose of the assignment, the needs of the parties, and the context surrounding them. Changes in the role differ, depending on the purpose of the assignment including; courtroom interpreting, medical interpreting, and educational interpreting from kindergarten through graduate courses. When translating between English and ASL interpreting occurs simultaneously, which requires the ability to hold incoming information while transmitting prior information. All these skills require a highly skilled interpreter who is able to multitask and is capable of being flexible and adaptive. These skills are even more complex for educational interpreters who work with various students, teachers, and staff that require them to take on additional roles not required from a community interpreter.

\subsection{Educational Interpreters}

The need for educational interpreters increased due to the emphasis on the least restrictive environment as stated under the Education for All Handicapped Children Act (EACHA or Public Law 94-142), which integrated deaf children with their hearing peers. This legislation led to communication barriers in the classroom; therefore, as more students were mainstreamed, the need for ASL interpreters in the classroom increased dramatically (Ackerman, Wolsey, \& Clark, 2018). The Rehabilitation Act of 1973 helped fund interpreter training programs (Newell, 1994); however, traditionally interpreter training curriculums were implemented as there were no other models available to provide guidance in the development of educational interpreter curriculums. Even today, programs tend to provide one or two courses for education interpretation within the traditional interpreter training programs. It appears that the status of this position is lower than that of a community interpreter and the pay tends to reflect this status. Currently, over 14,000 Educational Interpreter jobs are listed on ziprecruiter.com, and the national average salary is a bit over $\$ 52,000$ per year, but the range is broad with many schools hiring paraprofessionals rather than those with degrees. This salary is in contrast to community interpreters who earn at least $\$ 45,000$ as a beginning staff interpreter with an average certified interpreter earning at least $\$ 60,000$. A free-lance interrupter earns at least $\$ 35$ dollars an 
hour and the client pays for travel time to and from the city to the agency's address.

\subsection{Quality of Educational Interpreters}

Despite the 1973 Rehabilitation Act, a survey sent out in by Yarger (2001) to two selected states reflected that only $10 \%$ of educational interpreters attended and graduated from interpreting preparation programs. Yarger (2001) participants had taken at most one educational interpreting course during study in an interpreting program and many had never taken a formal course during their studies; therefore, it is not surprising that many feel unprepared for this job. This brings up an issue of the quality of educational interpreters and this concern is a long standing one as mentioned by Gustason (1985). Similarly, Schick (2008) found that most educational interpreters did not meet a common minimum standard on the Educational Interpreter Performance Assessment (EIPA). Given the lack of a curriculum for educational interpreters, there is an open question as to whether they come to their place of employment prepared, especially as Schick (2008) found that even those interpreters with the highest EIPA ratings who had been interpreting for at least 10 years only conveyed at best $40 \%$ of the teacher's lesson. Given these findings it is not surprising that educational interpreters noted a need to improve both their sign-to-English translating skills and their receptive skills (Yarger, 2001).

\subsection{Roles and Responsibilities of Educational Interpreters}

Antia and Kreimeyer's (2001) longitudinal study of three interpreters in inclusive (i.e., mainstream) classrooms focused on better understanding the roles and responsibilities of those working as educational interpreters. The responsibilities that were identified within these classrooms included interpreting between sign and spoken language for the deaf child, interpreting for their peers and the teacher, clarifying teacher directions and instructions for the deaf child, facilitating interactions between the deaf child and their hearing peers, tutoring the deaf child, and informing the teachers of the deaf child's progress. These roles were viewed differently by the classroom teacher and special educators. The teachers wanted the interpreters to adopt a full-participant model of interpretation to facilitate the deaf child's learning. In contrast, the special educators preferred the mechanical model of interpreting where only the first role of translating from spoken language to sign language occurred in the classroom. Special educators as well as administrators were concerned that the interpreter made the deaf child dependent on them and took over roles and responsibilities that should be performed by the teacher.

As found earlier in Yarger (2001), two of the three interpreters in Antia and Kreimeyer (2001) were hired as interpreter aids while the third was hired as an interpreter, pointing again to the issue of training. Additionally, interpreters in rural areas discussed taking on extra responsibilities including "caring for and 
maintaining personal FM systems, implementing speech lessons, and helping students work toward their goals in language development and content areas" (Yarger, 2001: p. 21). These findings highlight an issue within the field of educational interpreting, which is that there are no standards set for practice or even common agreement regarding the specific role and skill set needed to be an effective educational interpreter.

Recently, Smith (2016) developed the Educational Interpreter's Roles and Responsibilities (EIRR) checklist to begin to help Individualized Education Program (IEP) teams create more effective plans for mainstreamed deaf students. These roles in the EIRR are frequently overlooked in the training of educational interpreters, given that there are no standards. This lack of training leads many beginning educational interpreters to be unsure of their roles within the school system.

\subsection{Educational Interpreting Program Background}

Given these issues in how deaf children have been educated, the undergraduate program within the Deaf Studies and Deaf Education (DSDE) program at Lamar University was awarded an Office of Special Education Programs (OSEP) training grant to train educational interpreters. Historically, DSDE focused on training students to become $\mathrm{K}-12$ teachers of ASL as a second language. As this new training track was added, students frequently took both tracks to better be able to find a job. As they moved towards program completion and time for their internship, they were placed in a K-12 setting as a student teacher of ASL as a second language. Recently the program has expanded and students started to specialize; this change created the need for placements within educational interpreting settings rather than as an ASL student teacher.

As the program grew, requirements for both practicum and an internship in interpretation were added to provide students with the opportunity for real life experiences that classroom learning does not provide. Different internships can include working within an agency, an educational setting, or other community settings. However, finding these placements was difficult and many students were placed in community interpreting settings given that faculty had those types of connections and the local school districts were not offering placements in the field of educational interpreting.

Regardless of interpreting internship, many of these students found themselves hired to be educational interpreters. These jobs frequently do not require the individual to have passed either the Board for Evaluation of Interpreters (BEI) in Texas or the Registry of Interpreters for the Deaf (RID) certification tests. Therefore, students who were test avoidant or unable to pass these tests still were easily able to find jobs within their elected field of study.

As the reputation of the program increased, one faculty member was contacted by individuals in Alaska who were responsible for finding interpreters for deaf students within mainstream settings within the Alaskan school system. Given the rural locations of these schools they were using video remote inter- 
preting (VRI), which requires internet connection. This meant that when students went on field trips to learn vocational or survival skills, deaf students did not have access to everything that was discussed by their teachers. Therefore, they reached out to DSDE to ask if we had any students who needed internships. We perceived this situation as a rare opportunity for our student interpreters. Moreover, these internships were highly desired as the school was willing to pay these interns for both their travel to these remote rural sites as well as to give them a stipend during their internships.

In preparing for our students to accept these internships, we had several concerns. As mentioned earlier, one concern was related to preparing them to become educational interpreters as we did not have a course that focused on the roles of an educational interpreter, only specific vocabulary that is related to school content. We also became concerned that these students would struggle to adjust to the local culture of their placement. Based on these concerns, we decided it was imperative to follow these students, provide support, and learn from them so we could prepare the next cohorts more effectively. This plan reflects an ongoing concern regarding preparing interpreting students to become educational interpreters as noted by Gustason (1985), Schick (2008), and Yarger (2001). The question that emerges is whether there has been an improvement over time, and that question is where this study comes in, focusing on one specific interpreting program. Thus, the research questions were:

1) What were the interns' experiences?

2) Where were the gaps in knowledge of these interns during their internships?

3) What aspects of educational interpreter's role and responsibilities should we add to our curriculum and emphasize for future student interns?

\section{Method}

\subsection{Procedure}

As noted earlier, one faculty member was contacted by people in Alaska to see if we could provide interpreters for several of their more rural schools. Faculty discussed the opportunity with students. Given that students agreed to these internships, this project was designed prior to their leaving for Alaska. IRB approval was obtained from the university to collect student journals and videos of their reflections regarding their internships.

The focus of the study, as mentioned above, was to support the students and understanding how to improve the curriculum within the department based on their experiences; therefore, a qualitative content analysis design was implemented. Data was collected by the internship supervisor from the interns in terms of their journals which reflected their experiences, thoughts, and feelings. Some of these data points were videos of the interns reflecting on their experiences. Given that the department includes both deaf and hearing faculty who were participating on the project it was decided that the language of the student 
interactions would be in English, their native language, in order to best capture their thoughts, feelings, and experiences. IRB approval was a bit late, so the pre-interview was conducted by the internship supervisor as a journal entry. The focus was for students to discuss what they expected to occur during this internship. Thereafter, both the mid- and the final interviews were conducted in English by two different hearing faculty members. These interviews were then interpreted in ASL to be fully accessible to all authors. Interviews used an open-ended question "Tell us about your experiences up to this point." for the mid-interview and "What did you learn and what can you recommend to the department to improve these experiences for future students." for the final interview. Follow-up questions were asked to obtain clarification and to expand student answers.

\subsection{Participants}

Three different rural schools in native villages accepted student interns. Initially, five students were placed, two men (average age 23) and three women (average age 22). Participants included four hearing students and one hard of hearing student who was of Latin descent and had originally come to Texas from the east coast. The hearing students included one African American student and three white students, all of whom were born, raised, and had never traveled outside of the state of Texas. Two of the three placements had two interns each at the start of the project. The hard of hearing student was unable to adjust to the context and left the internship after several weeks. Therefore, the data is from the four students who completed their internships.

\subsection{Data Analysis}

A content analysis was conducted using all of the data from the journals as well as the interviews. Each author individually reviewed the data and identified codes. These codes were then discussed among the authors to decide on the final themes expressed by the student interns.

\section{Results}

With regards to the first and second research questions, three themes emerged from students' experiences as interpreting interns in K-12 educational settings in a rural area that was drastically different from their past experiences. The first theme was violation of student's expectations, the second theme was learning on the job; and the third theme was coming to love the job. Within these themes were sub-themes that are elaborated below. The third research question included the several recommendations from the interns regarding improvements to our program.

\subsection{First Theme: Violation of Interns' Expectations}

The first theme, violation of interns' expectations, includes cultural shock, cost 
of living, and weather as subthemes.

Cultural shock. Interns throughout the data analysis discussed their struggles with rural life, limited Internet access, the cost of living, and the weather. In terms of the rural area in which these interns were placed, the initial shock happened in terms of how long it took them to arrive at their schools. Students wrote in their journals that they had to fly on several larger planes and then take small private planes before they arrived. They later ended up on snowmobiles and ferries as they traveled.

Another shock was the size of the villages where they were located. One reported that there were only 200 people who lived in the town. Another wrote in her journal that she was "shock(ed). There are so many houses that look like school portables. It was honestly shocking to see how these people fit an entire family in the little houses." However, a pleasant cultural shock was that the community was extremely welcoming, integrating these students into the daily routines of their villages.

The internship supervisor chatted online via a video chat software program with these students almost daily, especially in the beginning as they adjusted to their new cultural experiences. There were many sessions with cold and frightened students who were not prepared for these new experiences. One student reported that "...apparently the night before a man froze to death ... one week ago 2 kids were lost. Anything can happen in these parts." These feelings eventually were replaced as noted below in coming to love it.

Given the current culture of being so strongly connected to the internet, our interns struggled from "withdrawal" without easy internet access. All interns noted that they were unable to watch videos on their computers as the internet was not strong enough to carry the signal. Two reported that they had to use the internet at the school as there was no internet where they were staying, stating, "Afterward I stayed at the school to have access to the WiFi to get some things done." Moreover, they were required to meet with the internship supervisor in ASL. One in frustration reported, "I am going to have to record myself signing and send it in because the internet here s__ks whenever I try to sign." This change in their lifestyle required them to adjust and find alternative entertainment options.

Cost of Living. The next shock was the cost of living. One cost that was difficult for those with vehicles was the cost of gas. Coming from Texas, where gas is relatively inexpensive, this price was something that they had not planned for and limited their ability to use their vehicle for anything but driving to school. The other shock regarding cost was buying the foods that they were used to having easy access to; for example, they all mentioned the high cost of soda. This shock was one that was reported frequently, as noted below:

Afterward the principal drove us to a grocery store were the other student and I could gather some food. I was taken aback by how much the food was in the state. I was warned ahead of time however, sometimes you just have 
to experience things yourself to truly understand.

In a similar way, another noted:

We stopped in the grocery store to get a few things and I was shocked by the prices. I knew ahead of time before arriving in Alaska that they would be high, but actually seeing them in person hurt a little.

One student called home and her parents began to send her "care packages" so that she could have snacks. However, this challenge was met by becoming used to native foods and dishes that were gathered from the land.

Weather. In contrast, weather was much harder for them. One student reported, "Stayed in and slept! Haven't been sleeping well. The wind outside makes a LOT of noise and kept waking me up." Another commented, "There is a huge storm that is going on outside today. The wind is blowing at $32 \mathrm{MPH}$ and there is snow everywhere. I tried to go out of the school but the snow was up to my knees." Given that they had grown up in Texas, this type of snow was amazing to them. Yet another reported:

It snowed today! I remember yesterday when they said it could snow a couple of feet. I feel like I was trying to convince myself that they said inches and not feet but when I walked outside this morning it was definitely a couple of feet.

Two interns were loaned a large van to drive during their internship. During this snowy period when they drove to school, they ran off the road. For the natives, this experience was common and they got out the chain and pulled them out of the ditch; however, the experience was much more vivid for these two young women who had never driven a large van, never mind in feet of snow, in their lives prior to their internships. The next challenge for these interns was related to their educational preparation as noted in research question two.

\subsection{Second Theme: Learning on the Job}

The second theme, learning on the job, revolves around interns' experiences as they learned on the job including a better understanding of: deaf students language and learning abilities, teachers expectations for deaf students, and the complex roles of educational interpreters.

Deaf students' language and learning abilities. Interns were surprised by what they encountered in their assigned educational institutions. They had been trained to interpret from voice to ASL as well as ASL to voice, but the deaf students who they were interpreting for in the schools basically had no language. The shock can be seen in one intern's comment; "Met with my student and kind of scared ... he doesn't use much ASL ... it's broken ASL ... most classes so far are hands on and not much talking." Another's student was described as having improved since coming to the school in the following way:

The student's teacher informed us that the child is a low language learner, 
where his parents don't sign and moved around a lot. When he arrived at the school last year, he only knew around 10 signs. Since then he has come a long way.

These deaf students left the interns puzzled as to how they were supposed to communicate, given that the child could not understand ASL. Their expectations were that they would facilitate communication as if they were community interpreters, which were completely inaccurate. The internship supervisor spent many hours helping these interns develop strategies to work with these students.

Teachers' expectations of deaf students. Interns were also shocked by teachers' expectations regarding what the deaf students were capable of doing in terms of school work. One noted, "They make my student do different work (mainly copy words from a book that he doesn't understand)." These deaf students were not expected to learn academic skills. One placement focused on teaching life skills to all of the students in the classroom so this intern was not as shocked by the teacher's low expectations. However, others were angry that teachers responded to these deaf students as if they were totally unteachable. One student wrote in her journal, "You are the teacher. It is your job to sit there and TEACH these kids. NOT hand them the answers."

Several interns reported that they were initially unprepared as to how to interpret the teacher's instructions in ways that would be understood by a student with such low levels of functional language. However, with time and coaching from the school interpreter they learned how to not only interpret but to convey information in ways that allowed comprehension. This experience was transformative for one intern as she recognized how the comprehension lighted up her student's face. The interns learned that educational interpreters often had to take on more than straightforward interpreting when working with deaf students.

The complex roles of educational interpreters. Interns shared through their journals and videos that they were taken aback by the lack of or low quality of interpreters for deaf students. One student was angry and reported:

We found out that the interpreter that we're observing isn't certified because when asked about the EIPA she responded with, "I don't know." Also, she told us this was her first interpreting job. To hear this was kind of a letdown [sic] because I was expecting [sic] to learn from an experienced ASL interpreter so that I can better my skills.

Others were dismayed at the skills of the interpreters within these schools. This intern reported:

Today was extremely frustrating all around. The beginning of the day we watched the interpreter sign a story to the kid. It was painful to see just a straight "English approach". I was really hoping to see a bilingual approach, but the interpreter signed each individual word. Most of the time a sign for a word was not conceptually accurate or is not used in ASL. 
These students had been trained not to use Signing Essential English (SEE) when interpreting but to create a conceptually accurate interpretation in ASL, following the grammar of that language. In contrast, SEE is a manual system of communication that attempts to exactly reproduce the vocabulary and grammar of English on the hands. The rationale for using SEE over ASL is that deaf and hard of hearing children have lower levels of reading skills and SEE can provide visual access to those grammatical components of English that are not components of ASL (see Nielsen, Luetke, McLean, \& Stryker, 2016). In contrast, linguists prefer to use ASL, a natural language, which they believe serves as the bridge to learning a second language (see Anderson, 1993). However, the student interns learned that in schools SEE is often used by interpreters and is frequently preferred or required.

Interns had not expected to take on the role of language teacher, tutor, and behavioral manager. Initially, they were stunned and did not understand how to perform the role of an educational interpreter. One intern reported being asked to provide a math lesson and becoming totally overwhelmed. With help from her interpreter supervisor, she did learn how to engage with her student in this way, which she found to be extremely rewarding.

As found in their words and their interviews, students were unprepared for these assignments in multiple ways. Initially, they were unprepared for the role of an educational interpreter and had to learn on the job how to function within this context. However, these interns proved to be resilient and took on the task of learning how to perform their job while also learning how to cope with the violations of their own expectations.

Figuring the day ended I started to leave and the principal was confused on why I was leaving. Overall that situation is dealt with and I'll be staying the full day from now on unless told otherwise by him. One of the Sped teachers informed him of what the role was for interpreters and he fully understood it ... but wants me to stay until the day was over with.

Here students were responding with the expectation that they functioned like community interpreters and were shocked to see the extra work required of them.

Another role was that they had to control their student's behaviors; an expectation that had never been taught in their course work. One intern noting; "I had an issue with my kid ... he basically said he 'wouldn't accept me' and then went on and either avoided when I was signing to him or just put his head down and again ignored me." Another reported, "He never looks at me unless we get onto him and then I still feel like he doesn't pay attention." The interns learned that educational interpreters will often continue to sign even when the student was "showing an attitude" or not watching. One noted that the middle school interpreter simply ignored these behaviors until the child stopped acting out. Another was interpreting for a school awards assembly while the deaf student looked away or played with his friends. However, she continued signing even though 
"(I) didn't think he even looked at me the whole hour I was interpreting this assembly. But, language was there if he needed it." During their placements they learned how to manage students' behaviors and to avoid power struggles when attempting to get them to pay attention.

Students also learned how to work with teachers in the school to improve the educational experiences for the deaf students. One noted, "It was interesting seeing the interpreter also as the tutor. That changed my perspective on the matter." Here the intern now understood that the child was unable to follow the lesson unless she went over the information one-on-one with him because his own language and comprehension levels were so low. Another noted that she had a conversation with the teacher about how the two of them could work together to support the deaf child. She was proud of her negotiation skills and reported that "it was a good professional conversation" and that she was proud of herself for keeping her "cool". Things went really smoothly as noted by one intern when she reported, "During reading ... I was able to sit and sign the morning story and was able to get the child involved. It was such a good time."

These comments show the growth in the interns' understanding of how an educational interpreter functioned within the classroom. One reported, "Before I used to think K-12 wasn't for me because I always thought it was ridiculous to have to be a kid's tutor as well as the interpreter." However, she learned that the language deprivation that these children had experienced required that the educational interpreter functioned in ways that helped to bridge these gaps; they were not only interpreting but serving as a language model and a coach to teach both world knowledge and cognitive strategies that the child had not yet learned. One student wrote in her journal, "I gained some new tools for my toolbox today to help me cope with my stress and my worries." Initially, the task of serving as an educational interpreter seemed impossible to these interns, but with mentoring and modeling they learned how to perform this extremely complex role.

Other duties that the interns were involved with included helping the teachers. One reported that she "spend the morning cutting out papers, findings signs for flashcards". Another helped the special education teacher grade papers in exchange for the teacher's help making worksheets to help the student understand the concept of "start, middle, and end". Another intern was given the task of developing a curriculum in sign to help the child understand puberty. She researched the signs that the student needed for this lesson to help him understand this important developmental process. These roles were not what these interns had expected when they arrived at their schools, but their experiences helped them understand how and why these tasks are a vital part of the role of an educational interpreter. This new comprehension lead to their comments about the third theme of enjoying their work as their comprehension expanded about the roles of an educational interpreter.

\subsection{Third Theme: Coming to Love It}

The third theme, coming to love it, emerged from the data, including appre- 
ciating the outdoors and the rural lifestyle, and "getting it" about $K-12$ educational interpreting and developing effective strategies. Most interns went to their internship placement with a positive outlook, expecting an adventure and an immersive experience. It appears it did not occur to them that they would fall in love with the career of K-12 interpreting and the lifestyle. A few interns, as a result, applied to work in the state.

Appreciating the outdoors and the rural lifestyle. Prior to their internship, interns shared that they were looking forward to the trip and learning about the lifestyle and culture of where they would be placed; they were not disappointed.

As students were transported to their internship placement, they had to fly as it was difficult to travel via a road vehicle. They were taken aback but some of them appreciated the experience as one shared, "The flight over was so pretty. The landscape and the way the sun reflected off of the snow were breathtaking." Furthermore, the interns immersed themselves into the community life as much as they could including participating in some hunting and trapping activities as stated by one intern, "After school some of the staff and myself went out snowshoeing again to set up traps for foxes and rabbits. It was so much fun." Not only that, but they also participated in culinary delicacies differing from that of their upbringing, like eating an oyster. Two interns reported, "We both ate a raw oyster. It was quite an experience." Students learned to eat what the villagers ate, including blubber, caribou, and local fish. One intern mentioned, "If they didn't catch or trap it, they went without food in the winter." They learned to respect the idea of living off the land. This cultural awareness also included learning new ways to "play" without technology in a climate that was so different than the subtropical one of their own homes.

Here they learned to enjoy the outdoors and winter activities, such as sledding and snowshoeing. One student expressed her delight with, "After school I went snowshoeing with one of the teachers from the school. It was so much fun! I got waist deep in snow and had to struggle to get out. It was a blast." For some interns, simply going outside was an experience by itself as shared by a student, "It was odd because around the beach I found animal bones and ship remains." Here the student had to re-frame her experiences of what you find on a beach that is a working one, unlike her experiences with beaches in her home state. Several interns discussed their appreciation of the forest, lakes, and rivers. They found them peaceful and used them as a way to de-stress.

"Getting it" about K-12 interpreting and developing effective strategies. After several years of studying to become an interpreter, all interns went to their internship with certain expectations and beliefs about K-12 interpreting. After a few weeks, they started to understand and embrace the role of K-12 interpreters, which is more than just interpreting. Rather, it is more about working with deaf students to provide support and guidance tied in with their interpreting duties. For instance, as noted in the second theme, an intern realized a part of K-12 interpreter's responsibilities was to help manage behavior. She stated, "I made a deal if he showed up for all his classes and had good behavior during the week 
I'd let him have a soda every Friday after school." One intern found herself placed into the role of a chaperone, helping the girls get ready for their prom. She later found it difficult to maintain boundaries, chatting with the principal to learn how to balance these various roles. Here the interns noted an increasing understanding that had not been provided during their coursework.

The interns learned that tutoring is part of the role of an education interpreter, which is not true of community interpreting. An intern expressed this realization:

It was interesting seeing the interpreter also as the tutor. The [sic] changed my perspective on the matter... But now I am realizing that if you don't sit down with the student and go over the worksheet with them, they aren't going to understand what the heck is going on, because you are their access to language and understanding.

Interns learned that if they wanted to communicate with their deaf students they needed to develop educational strategies that provided more concrete information to allow their deaf students' access to the lessons. These more concrete strategies then allowed interpretation that was effective and allowed the deaf students to comprehend the content of the lesson.

Also, interns found themselves being creative at solving problems as in how to make themselves more visually accessible as shown by a student who said:

The real challenge is the fact that I was interpreting in a black light situation and she was [not] able to understand me. I asked if I could borrow some white gloves and it made my hands pop. It was a learning experience, but it was good to see the joy on her face when she was able to play like a normal person with her friends.

Most of all, interns realized the connections they made with their students outweighed the cons of other aspects of K-12 interpreting as shared by an intern:

She learned so much and she had fun doing it. I believe that is all that matters is that they are learning and also being able to see the joy in it. I love that. The best part of my day was the end. I was helping the pre-k-er get ready to go home and I told her bye and she gave me a hug for 5 minutes. She needed it ... It warms my heart to know that I am able to make a difference.

These insights overcame the initially misconceptions about the roles of K-12 educational interpreters and caused these interns to rethink their career goals.

These components of being an educational interpreter initially created confusion and even resistance among the interns. However, with time they learned that simply providing a translation of what was happening in the classroom was still not accessible for the deaf students with whom they were working. Therefore, they learned to model their behaviors after others in the school system. Understanding the struggles for these deaf students helped them to change their behaviors and find strategies to allow true access, not only to language but to 
comprehension. They began to understand why teachers had provided worksheets and did not teach these severely language delayed deaf children. Importantly, they helped the community understand that deaf children were not uneducable but needed access to language. Finally, they learned that their decisions were neither right or wrong, but these outcomes provided them with learning opportunities.

Recommendations from students. In regard to the third research question, during the final interview, interns were directly asked what their recommendations would be to improve the program. Students struggled with providing broad abstract answers, rather they provided a few concrete suggestions.

First, all interns felt that there was a need for more coursework specifically on educational interpreting. During their time within the program there was neither a specific course or integrated coursework in other interpreting courses regarding the roles and expectations for educational interpreters. All of the interns believed that this lack of educational content lead to their own misunderstanding when they arrived at their placements.

Another recommendation centered around preparation for the experience. Interns connected this recommendation to the first one in terms of coursework. They felt their initial entry into the placement would have been smoother if they had time to focus on the roles of an educational interpreter as well as the cultural expectations that they would face in these placements. They explained that the program should emphasize the expectations of an educational interpreter rather than be prepared to do community interpreting. They suggested observations of local programs near the school to better understand the concept of an educational interpreter.

The final recommendation was in regard to the logistics of their housing. Initially, the goal was to place two interns at each site. However, an odd number of interns signed up for the course, leaving one intern by himself from the beginning. This specific intern was extremely self-reliant and rapidly developed effective strategies to work with his deaf student as well as how to integrate into the small, rural, and highly conservative community. A second placement initially began with two interns, which unfortunately rapidly became an issue. The one intern left the placement as he was not resilient and could not adapt to the roles of an educational interpreter as his expectations were that he would function ONLY as a facilitator for communication. His placement was ended by the internship superior and the chair of the department, leaving the second intern by herself. Interestingly, this change allowed her to re-frame her expectations and she developed strategies that allowed her to function well within the role of an educational interpreter. She has since taken a job in Alaska. Interesting, the remaining pair had a difficult time together as they shared housing. One intern was much more of an introvert than the other, causing high levels of stress outside of school. However, during the school day both learned to function well and were integrated into the school culture. This pair recommended that each intern have a separate space to provide them with a place to de-stress. 
These were the only recommendations that were offered, even with additional follow up questions. Students themselves were surprised that they had enjoyed the experience and reported that now they could see themselves in the role of an educational interpreter. They reported feeling that they were unprepared for the experience, but they had only a few comments about how to improve the curriculum. Some conclusions will be presented later in the discussion to expand their own ideas.

\section{Discussion}

The content analysis provided information about the three research questions. Students had expectations prior to leaving and most of those were violated during the internship. They reported large and clear gaps in their knowledge of the roles and responsibilities of educational interpreters and were able to suggest some changes for the department's curriculum. Interestingly, these recommendations were general and vague about what they felt would have better prepared them to "hit the ground running" when they arrived at their placements. Next, we expand on these ideas and how they related to what is known about internships and educational interpreting.

The theme violation of student's expectations is consistent with previous work on intercultural competence and student interns (Chuprina, 2001; Marginson, 2014; Schmid, 2009; Sinicrope et al., 2012). Students' experiences of culture shock and how they overcame them in the current study concur with the process of intercultural competence reported by Chuprina (2001) and Marginson (2014). Similar to these previous studies, the students reflected on their experiences and shaped themselves to new changing identities and expectations.

The findings of this study show that regardless of prior experiences and training, internship experiences offered opportunities that helped to reframe the interns' perceptions of educational interpreting in K-12. The interns' experiences follow findings in previous research which reported the educational interpreter's job was not merely to interpret but included non-interpreting activities such as language modeling, tutoring, facilitating peer interaction, teaching sign language, providing student' feedback on assignments, and other classroom aide responsibilities (Antia \& Kreimeyer, 2001; Beal-Alvarez \& Scheetz, 2015; Humphrey \& Alcorn, 1994; Jones, Clark, \& Soltz, 1998; Yarger, 2001).

Additionally, the interns found themselves in a situation where the deaf students that they were to interpret for had limited sign language abilities. Their deaf students' experiences with access to sign language only occurred in the school setting when it was provided by educational interpreters (Beal-Alvarez \& Scheetz, 2015). Due to the students' delays in language acquisition, the interns' job resembled that used with young children; they not only had to interpret the teacher's words but had to facilitate comprehension and the acquisition of language (Seal, 1998). With this in mind, the educational interpreters' roles change over time, based on the students' age and language experience (Humphrey \& 
Alcorn, 1994; Zawolkow \& DeFiore, 1986).

In the current study, interns took coursework that was designed to prepare community interpreters. They had only one course that focused on educational interpreting, called K-12 Interpreting; however, this course only focused on vocabulary for high school content. Given this curriculum, interns had never had hands-on experience. This knowledge gap is clearly seen in the interns' misunderstanding of the roles and responsibilities of an educational interpreter.

An interesting finding from the content analysis was that the students could identify the gaps in their knowledge as noted by the findings related to research question two but were only superficially aware of what they needed when explicitly asked for recommendations to improve the program (as asked for in research question three). If one more closely looks at their responses, it becomes clear that they now had hands on experience in regard to functioning as an interpreter in the classroom but were still unclear about the exact roles of an educational interpreter. These findings are similar to those of Antia and Kriemeyer (2001), as well as Schick (2008) and Yarger (2001) in that there are no standards in place for educational interpreters.

Interestingly, there has been a push to improve educational interpreting training for several decades, beginning with a national task force in 1985 which examined and clarified roles and responsibilities, as well as develop training and certification for educational interpreters (Stuckless, Avery, \& Hurwitz, 1989). Dahl and Wilcox (1990) emphasized the importance of these needs as they found only three out of 45 interpreting programs were preparing educational interpreters. Moreover, Schick, William, and Bolster (1999) emphasized that there was no certification specifically for educational interpreters, and most interpreters were not qualified to provide an adequate interpretation of classroom discourse. Moreover, these interpreters did not provide children with models of language that allow children to learn content and language. Therefore, Schick (2008) created the EIPA to serve this function. However, Schick (2008) found that even the best educational interpreters are still unable to effectively convey more than $40 \%$ of the classroom content. Given this state of affairs, Smith (2016) and her EIRR can be used to build a curriculum for educational interpreting programs that may help to remediate these gaps.

Smith's (2016) EIRR, which focuses on the components of an Individual Education Plan (IEP) for an educational interpreter, can be used to build courses and content that will more effectively prepare students to go into the classroom to work with deaf students as well as their teachers. Smith (2016) notes six different areas that are included in effective educational interpretation on her EIRR Guiding Checklist. She suggests that these areas be included within the IEP developed for each deaf student to help the educational interpreter provide effective interpretation. The first area is called essential considerations. This area focuses on what is needed by the student for effective interpretation; does the deaf student need either one-on-one interpreting, a teacher of the deaf, or does the educational interpreter needs more training to be effective. The second area 
is labeled interpretation required and specifies which content areas and courses require interpretation. The third component is primary communication modalities and focuses on which language (ASL or English) or modality (e.g., SEE, listening and spoken language, cued speech, total communication) is used by the deaf student. The fourth area is called language facilitation during interpretation. Here it is suggested that the IEP specifies the types of tasks expected of the educational interpreter and these tasks need to be included in educational interpreting training programs. For example, this area discusses whether the child needs to be taught sign language or provided with supplemental explanations. Fifth is called accommodations and focuses on how to best convey the information to the deaf child. Examples include preferential seating, test administration, translating dictated answers and rewarding instructions. The sixth and final part is labeled related and supplemental services. This part includes the components most likely not taught in traditional community-based interpretation courses including; collaboration with teachers, supplemental academic support, social emotional and behavioral support, as well as audiological equipment support. It becomes clear when looking at Smith's (2016) EIRR Guiding Checklist that these components relate directly to the gaps in our interns' knowledge regarding their expected roles and responsibilities. This information in conjunction with the interns' own recommendations leads to suggestions for improvement within our educational interpreting track.

\section{Recommendations for Educational Interpreter Programs}

The finding from the current study has implications for the DSDE department as it relates to educational training. The following recommendations can better prepare DSDE interpreting students and offer suggestions for other educational interpreting programs to support graduating students entering the classroom understanding the many roles and skills required.

First, based on the previous and current study finding, there is a need to differentiate between community and educational interpreting. So, as opposed to having only one class labeled K-12 Interpreting, the educational interpreting program needs to focus on specific area for training within the schools. Previous research and the national taskforce report (Dahl \& Wilcox, 1990; Kluwin, 1994; Winston, 1985; Stuckless, Avery, \& Hurwitz, 1989) can guide the department to define and design an elective program that specifically targets educational interpreters. In developing the K-12 Educational Interpreting program, Smith's (2016) EIRR checklist can serve as an outline for the competencies that should be present.

The second recommendation is that all interpreting courses include content related to the EIRR expectations and competencies. For example, the department has three courses that teach the foundations of interpreting. It becomes important that these courses integrate the six components into their structure rather than solely focus on community interpretation.

The third recommendation is that the Practicum course focuses on placements within schools to prepare DSDE students for their internships and future 
jobs within educational settings.

The fourth recommendation is that at least $50 \%$ of the Interpreting Internships should be within educational settings.

The fifth recommendation is that the course "Interpreting for Diverse Deaf Communities" include information regarding intercultural competency.

The sixth recommendation is that the course "Professional Responsibilities" develops students' expectations regarding their internship, including; living arrangements, financial issues, and how to develop "soft skills" including accepting feedback and constructive criticism.

The final recommendation is for the national interpreting board to review roles and responsibilities associated with educational interpreters. The board should consider a specific licensure for K-12 educational interpreters that stipulates clearly the associated ethics, self-advocacy, and competencies.

These recommendations will help to improve the curriculum based on interns' experiences and feedback (Kramer-Simpson, 2018). Additionally, this information in conjunction with the newest research can help design educational interpreting coursework that will provide the most effective support for deaf students in mainstream programs. This support will thereby indirectly improve deaf education as it will prepare educational interpreters to work effectively with teachers. This interaction between the educational interpreter and the teacher should lead to more effective outcomes for deaf students as it will provide a "road map" for just-in-time changes within the ongoing educational experiences as well as the IEPs for these mainstreamed deaf students.

Limitations. This study is a beginning in our understanding of how interns from interpreter training programs experience interpreting in the classroom with deaf students who have serious language delays, frequently form language deprivation (Hall, Levin, \& Anderson, 2017). However, the study includes a small sample in an extremely isolated situation and cannot be generalized to other contexts.

\section{Conclusion}

Due to established laws, the increasing need of interpreters, and the expansion of specialized interpreters, there is a need for interpreter preparatory programs to adjust accordingly. These changes have occurred within the last fifty years and more rapidly in the last thirty year; however, research and educational preparation have lagged behind. Due to this concern, we tracked four student interpreter interns at various educational settings, and with the extra layer of being placed in a community different from students' upbringings, we aimed to work with these interns to provide guidance and support. Throughout the study, students shared through journals, written, and videotaped, their experiences, and three themes were identified, providing us with important insights in how to improve our programs as well as providing information other similar programs could capitalize. 
Suggestions were made by interns, which we took into consideration, as well as using findings to further these recommendations. Student interns underwent shock by underestimating cultural differences, abilities of deaf students, and expectations of educational interpreter's roles. However, these interns realized that educational interpreting is more than just interpreting, and it also includes providing deaf students with specific guidance and support. They grew to appreciate this aspect of being an educational interpreter, and at least two of them were interested in continuing as educational interpreters. Educational interpreters fill in a much-needed gap for deaf students, and this study provides a glimpse in how to advance this field.

\section{Acknowledgements}

We would like to acknowledge the contribution of Cain Chiasson who was the internship supervisor for this course and Zanthia Smith the program director for the BA in ASL-Interpreting.

\section{Ethics}

All participants gave consent to participate in the project which was also approved by the university's IRB. Data from the one participant who left the internship were not used in this project, as he withdrew from the study.

\section{Conflicts of Interest}

The authors declare no conflicts of interest regarding the publication of this paper.

\section{References}

Ackerman, J. A., Wolsey, J. A., \& Clark, M. D. (2018). Location of L2/Ln Sign Language Pedagogy. Creative Education, 9, 2037-2058. https://doi.org/10.4236/ce.2018.913148

Aldas, T., Crispo, V., Johnson, N., \& Price, T. A. (2010). Learning by Doing: The Wagner Plan from Classroom to Career. Peer Review, 12, 24-28. https://search.proquest.com/docview/822747477? accountid=7043

Anderson, S. R. (1993). Linguistic Expression and Its Relation to Modality. In G. R. Coulter (Ed.), Current Issues in ASL Phonology (pp. 273-290). Cambridge, MA: Academic Press. https://doi.org/10.1016/B978-0-12-193270-1.50018-2

Antia, S. D., \& Kreimeyer, K. H. (2001). The Role of Interpreters in Inclusive Classroom. American Annals of the Deaf, 146, 355-365. https://doi.org/10.1353/aad.2012.0142

Beal-Alvarez, J. S., \& Scheetz, N. A. (2015). Preservice Teacher and Interpreter American Sign Language Abilities: Self-Evaluations and Evaluations of Deaf Students' Narrative Renditions. American Annals of the Deaf, 160, 316-333.

https://www.jstor.org/stable/26235220 https://doi.org/10.1353/aad.2015.0027

Chinomona, R., \& Surujlal, J. (2012). The Influence of Student Internship Work Experience on Their Self-Improvement and Professionalism in Sport Management. African Journal for Physical Health Education, Recreation and Dance, 18, 885-899.

https://hdl.handle.net/10520/EJC128369 
Chuprina, L. (2001). The Relationship between Self-Directed Learning Readiness and Cross-Cultural Adaptability in U.S. Expatriate Managers. Unpublished Doctoral Dissertation, Knoxville, TN: University of Tennessee.

Coco, M. (2000). Internships: A Try before You Buy Arrangement. SAM Advanced Management Journal, 65, 41-47.

Cook, S. J., Parker, R. S., \& Pettijohn, C. E. (2004). The Perceptions of Interns: A Longitudinal Case Study. Journal of Education for Business, 79, 179-185. https://search.proquest.com/docview/202821430?accountid=7043

Dahl, C., \& Wilcox, S. (1990). Preparing the Educational Interpreter: A Survey of Sign Language Interpreter Training Programs. American Annals of the Deaf, 135, 275-279. https://doi.org/10.1353/aad.2012.0549

Gavigan, L. (2010). Connecting the Classroom with Real-World Experiences through Summer Internships. Peer Review, 12, 15-19. https://search.proquest.com/docview/822747390?accountid=7043

Gustason, G. (1985). Interpreters Entering Public School Employment. American Annals of the Deaf, 130, 265-266. https://doi.org/10.1353/aad.2012.0970

Hall, W. C., Levin, L. L., \& Anderson, M. L. (2017). Language Deprivation Syndrome: A Possible Neurodevelopmental Disorder with Sociocultural Origins. Social Psychiatry and Psychiatric Epidemiology, 52, 761-776. https://doi.org/10.1007/s00127-017-1351-7

Humphrey, J. A., \& Alcorn, B. J. (1994). So You Want To Be an Interpreter? An Introduction to Sign Language Interpreting. Amarillo, TX: H \& H Publishers.

Janet, E. (2009). The Power of Experiential Education. Liberal Education, 95, 24-31. https://eric.ed.gov/?id=EJ871318

Jones, B. E., Clark, G. M., \& Soltz, D. F. (1998). Characteristics and Practices of Sign Language Interpreters in Inclusive Education Programs. Exceptional Children, 63, 257-268. https://doi.org/10.1177/001440299706300209

Kluwin, T. N. (1994). Interpreting Services for Deaf Youngsters Who Are Deaf in Local Public School Programs. Journal of American Deafness and Rehabilitation Association, 28, 21-29.

Kramer-Simpson, E. (2018). Feedback from Internship Mentors in Technical Communication Internships. Journal of Technical Writing and Communication, 48, 359-378. https://doi.org/10.1177/0047281617728362

Marginson, S. (2014). Student Self-Formation in International Education. Journal of Studies in International Education, 18, 6-22. https://doi.org/10.1177/1028315313513036

Newell, W. J. (1994). A Profile of Professionals Teaching American Sign Language. American Annals of the Deaf, 86, 19-36. https://doi.org/10.1353/sls.1995.0009

Nielsen, D. C., Luetke, B., McLean, M., \& Stryker, D. (2016). The English-Language and Reading Achievement of a Cohort of Deaf Students Speaking and Signing Standard English: A Preliminary Study. American Annals of the Deaf, 161, 342-368. https://doi.org/10.1353/aad.2016.0026

O’Neil, N. (2010). Internships as a High-Impact Practice: Some Reflections on Quality. Peer Review, 12, 4-8. https://search.proquest.com/docview/822747510?accountid=7043

Schick, B. (2008). A Model of Learning within an Interpreted K-12 Setting. In M. Marschark, \& P. C. Hauser (Eds.), Deaf Cognition: Foundations and Outcomes (pp. 351-386). New York: Oxford University Press.

Schick, B., William, K., \& Bolster, L. (1999). Skill Levels of Educational Interpreters Working in Public Schools. The Journal of Deaf Studies and Deaf Education, 4, 144-155. https://doi.org/10.1093/deafed/4.2.144 
Schmid, A. (2009). Intercultural Competence. In L. Kirjazovaite, (Ed.), Reflections Based on Ideas from Intercultural Competence, Round Table. Italy, Rome: SALTO Cultural Diversity Resource Center.

Seal, B. C. (1998). Best Practices in Educational Interpreting. Needham Heights, MA: Allyn \& Bacon.

Simons, L., Fehr, L., Blank, N., Connell, H., Georganas, D., Fernandez, D., \& Peterson, V. (2012). Lessons Learned from Experiential Learning: What Do Students Learn from a Practicum/Internship? International Journal of Teaching and Learning in Higher Education, 24, 325-334.

Sinicrope, C., Norris, J., \& Watanable, Y. (2012). Understanding and Assessing Intercultural Competence: A Summary of Theory, Research, and Practice.

Smith, K. R. (2016). Towards the Validation of the Educational Interpreter Roles and Responsibilities (EIRR) Guiding Checklist: Exploring Expert Stakeholders' Perspectives. Unpublished Doctoral Dissertation, Lubbock, TX: Texas Tech University.

Stichman, A. J., \& Farkas, M. A. (2005). The Pedagogical Use of Internships in Criminal Justice Programs: A Nation-Wide Study. Journal of Criminal Justice Education, 16, 145-179. https://doi.org/10.1080/1051125042000333523

Stuckless, E. R., Avery, J. C., \& Hurwitz, T. A. (1989). Educational Interpreting for Deaf Students: Report of the National Task Force on Educational Interpreting. Rochester. New York: National Technical Institute for the Deaf.

Winston, B. (1985). Mainstreaming: Like It or Not. Journal of Interpretation, 2, 117-119.

Yarger, C. C. (2001). Educational Interpreting: Understanding the Rural Experience. American Annals of the Deaf, 146, 16-30. https://doi.org/10.1353/aad.2012.0074

Zawolkow, E., \& DeFiore, S. (1986). Educational Interpreting for Elementary and Secondary Level Hearing-Impaired Students. American Annals of the Deaf, 131, 26-28.

https://doi.org/10.1353/aad.2012.0791 